\title{
La « cinématogravure »
}

\section{Guy Braun}

\section{(2) OpenEdition}

\section{Journals}

Édition électronique

URL : http://journals.openedition.org/rbnu/1407

DOl : $10.4000 /$ rbnu. 1407

ISSN : 2679-6104

\section{Éditeur}

Bibliothèque nationale et universitaire de Strasbourg

\section{Édition imprimée}

Date de publication : 1 novembre 2015

Pagination : 96-105

ISBN : 9782859230616

ISSN : 2109-2761

\section{Référence électronique}

Guy Braun, "La « cinématogravure » », La Revue de la BNU [En ligne], 12 | 2015, mis en ligne le 01 mars 2020, consulté le 19 décembre 2020. URL : http://journals.openedition.org/rbnu/1407 ; DOI : https:// doi.org/10.4000/rbnu. 1407

\section{(ब) $10(0$}

La Revue de la BNU est mise à disposition selon les termes de la Licence Creative Commons Attribution - Pas d'Utilisation Commerciale - Partage dans les Mêmes Conditions 4.0 International. 


\section{La «cinématogravure»}

C'est parce qu'il existe chez les grands réalisateurs le désir d'un retour à l'origine de la peinture, du dessin et donc de la gravure que m'est venue l'idée de rendre hommage au cinématographe par une série, encore inachevée et sans doute inépuisable, que j'intitule " cinématogravure ". Il s'agit de " mettre en lumière " certaines images furtives, qui ne sont pas directement impliquées dans l'intrigue - souvent imperceptibles pour le spectateur, car noyées dans le flux de l'émotion. En faisant ce chemin à rebours, je suis les traces d'Etienne-Jules Marey. Sa quête scientifique du mouvement décomposé et son refus de l'artifice de l'image animée redonnent au cinéma sa dimension graphique.

Dans Metropolis, et plus généralement dans le cinéma expressionniste, chaque plan est pensé comme une œuvre. On y trouve à la fois la force du cadre chère à Jacques Callot et la densité des contrastes chère à Rembrandt. En ce sens le noir et blanc confronte naturellement la modernité à la tradition. L'univers gravé affleure dans l'œuvre de grands réalisateurs, comme chez Bergman : dans Le Septième sceau, on songe à Dürer et La Nuit des forains évoque le monde de Callot. Des films plus récents, bien qu'en couleur (Un Homme et une femme), trahissent cet émerveillement de l'instant fugace où la narration passe au second plan.

L'arrêt sur image impose la réflexion et dépasse en intensité le torrent d'informations invisibles. C'est de l'observation du détail que surgit l'émotion.

\section{Guy Braun}




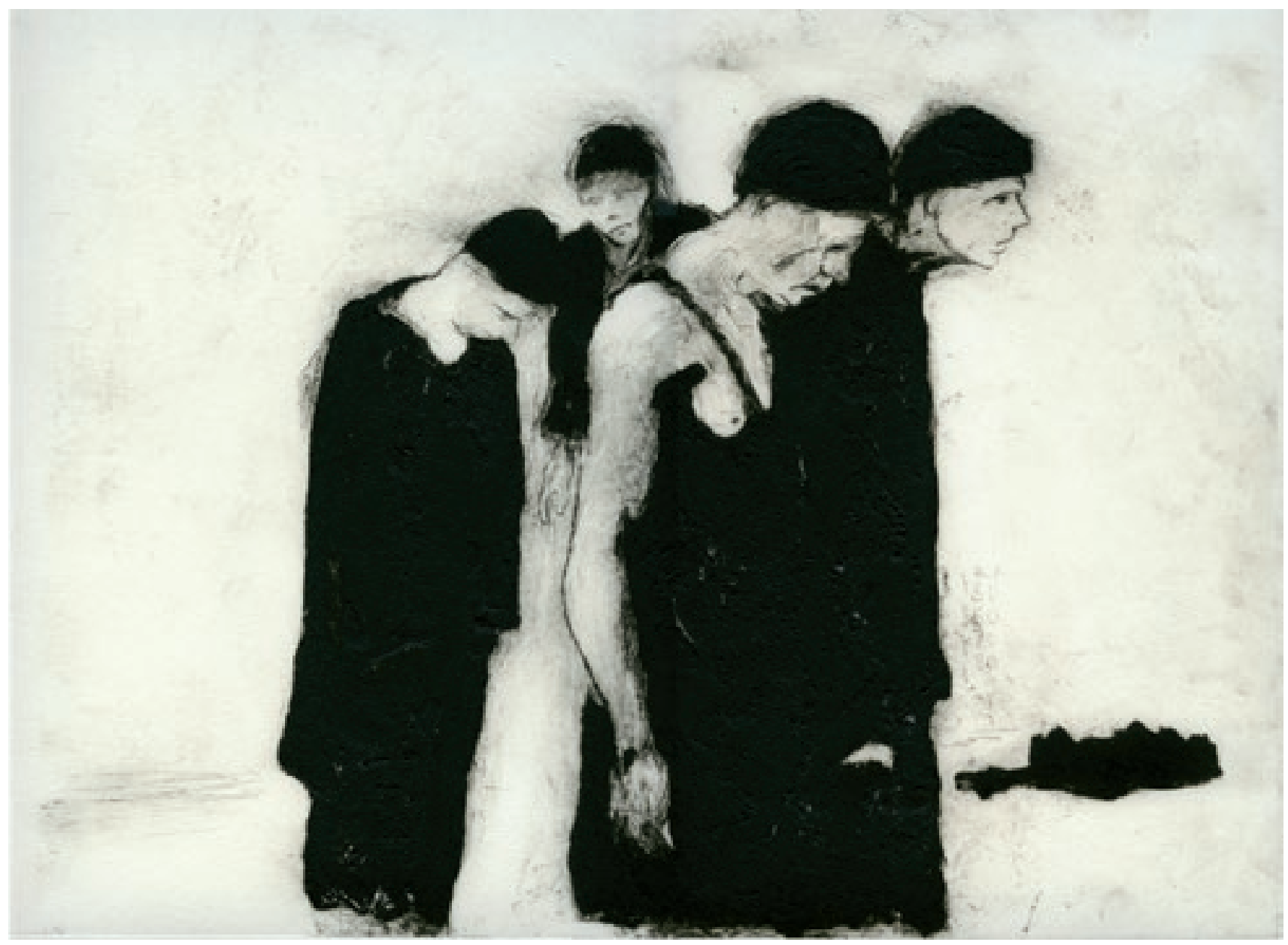

Metropolis 1 (Fritz Lang, 1927) 


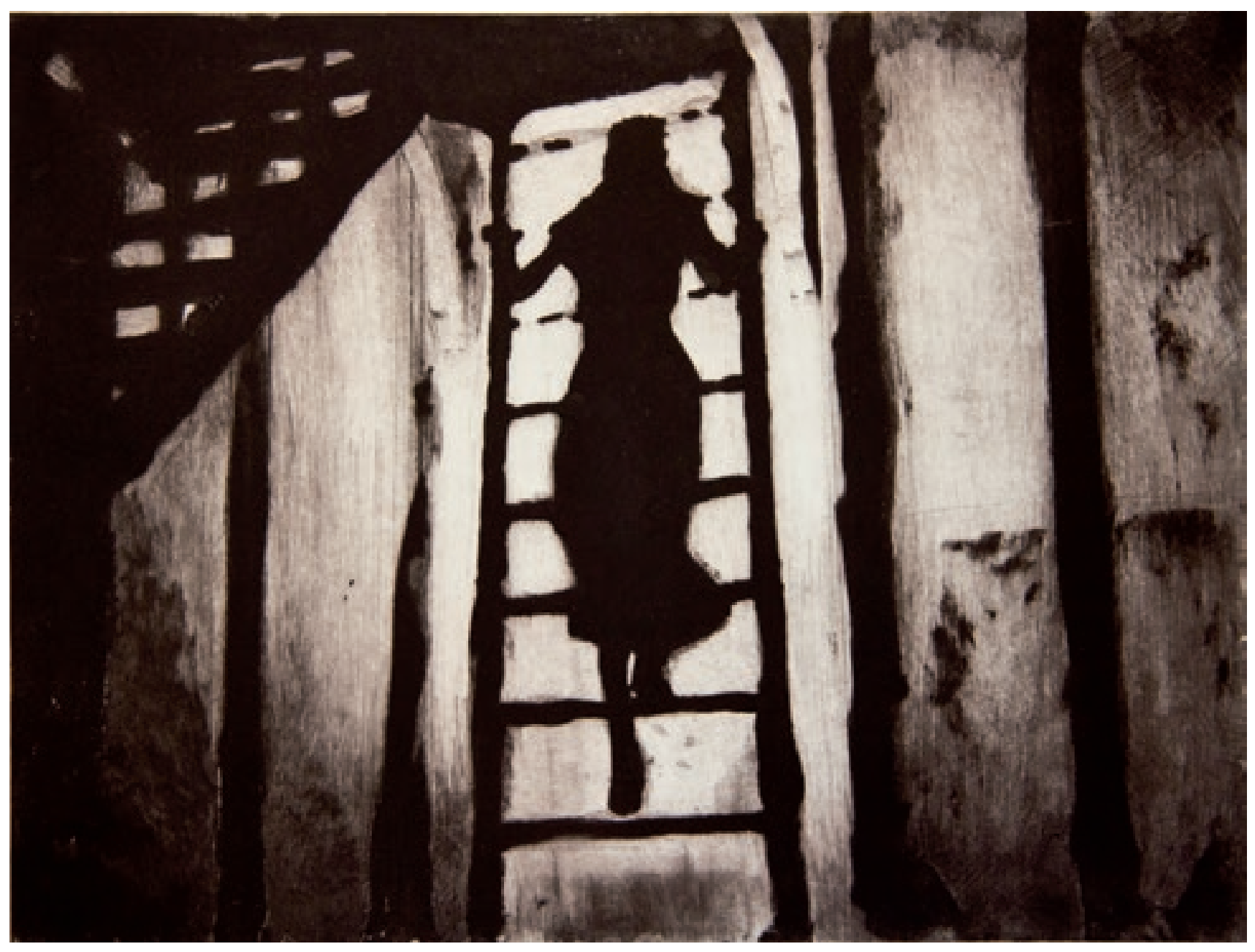

Metropolis 2 


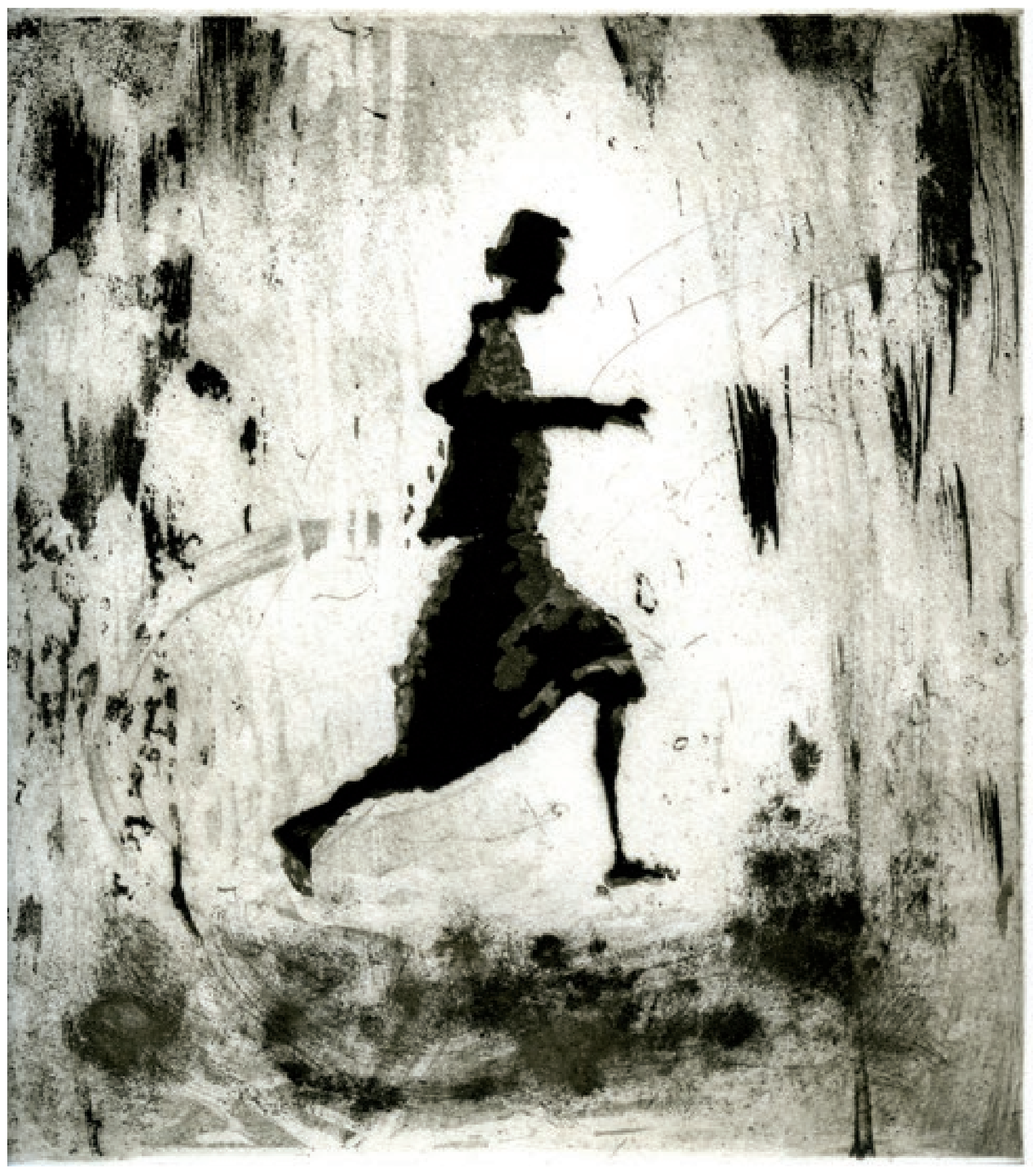

Metropolis 3 


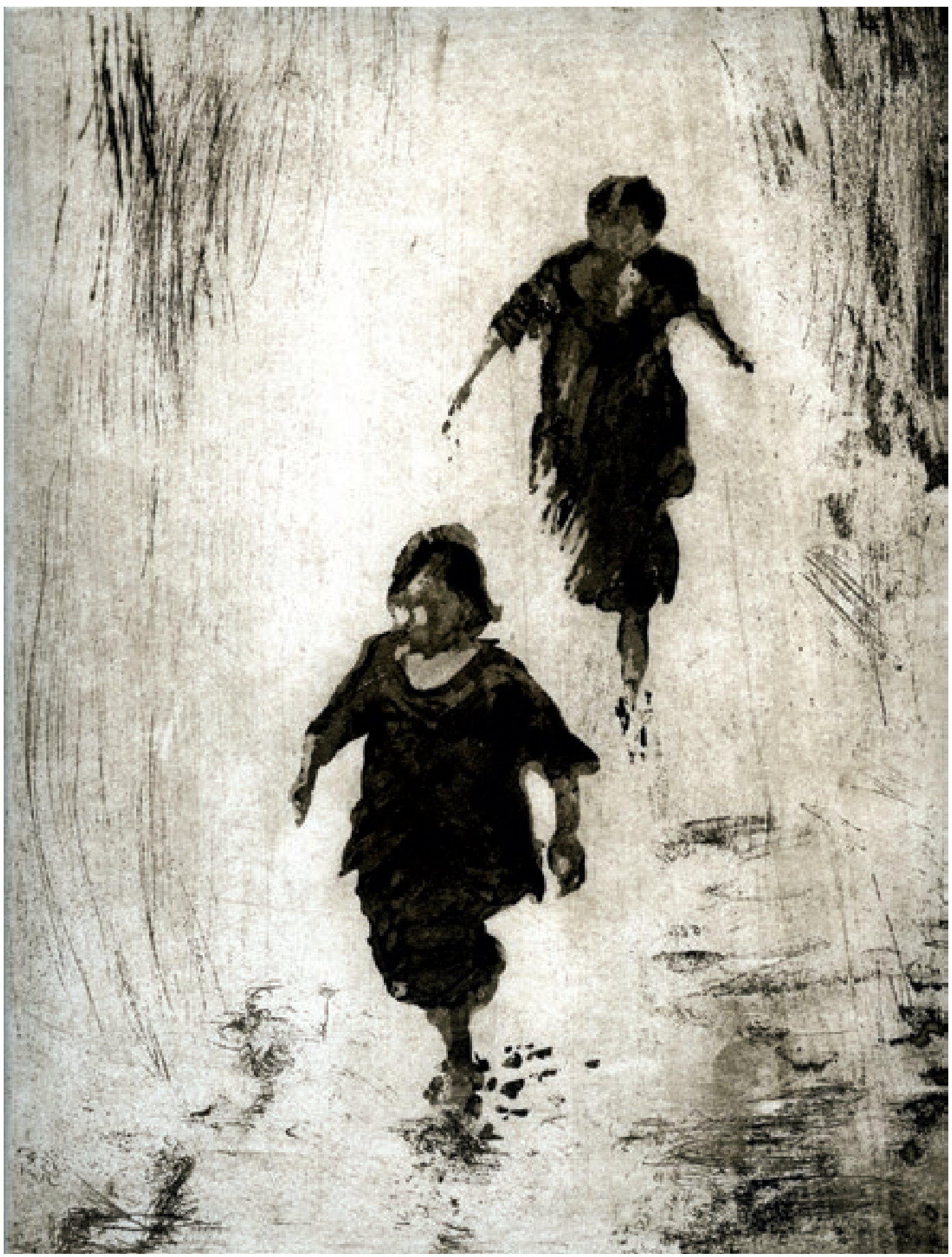




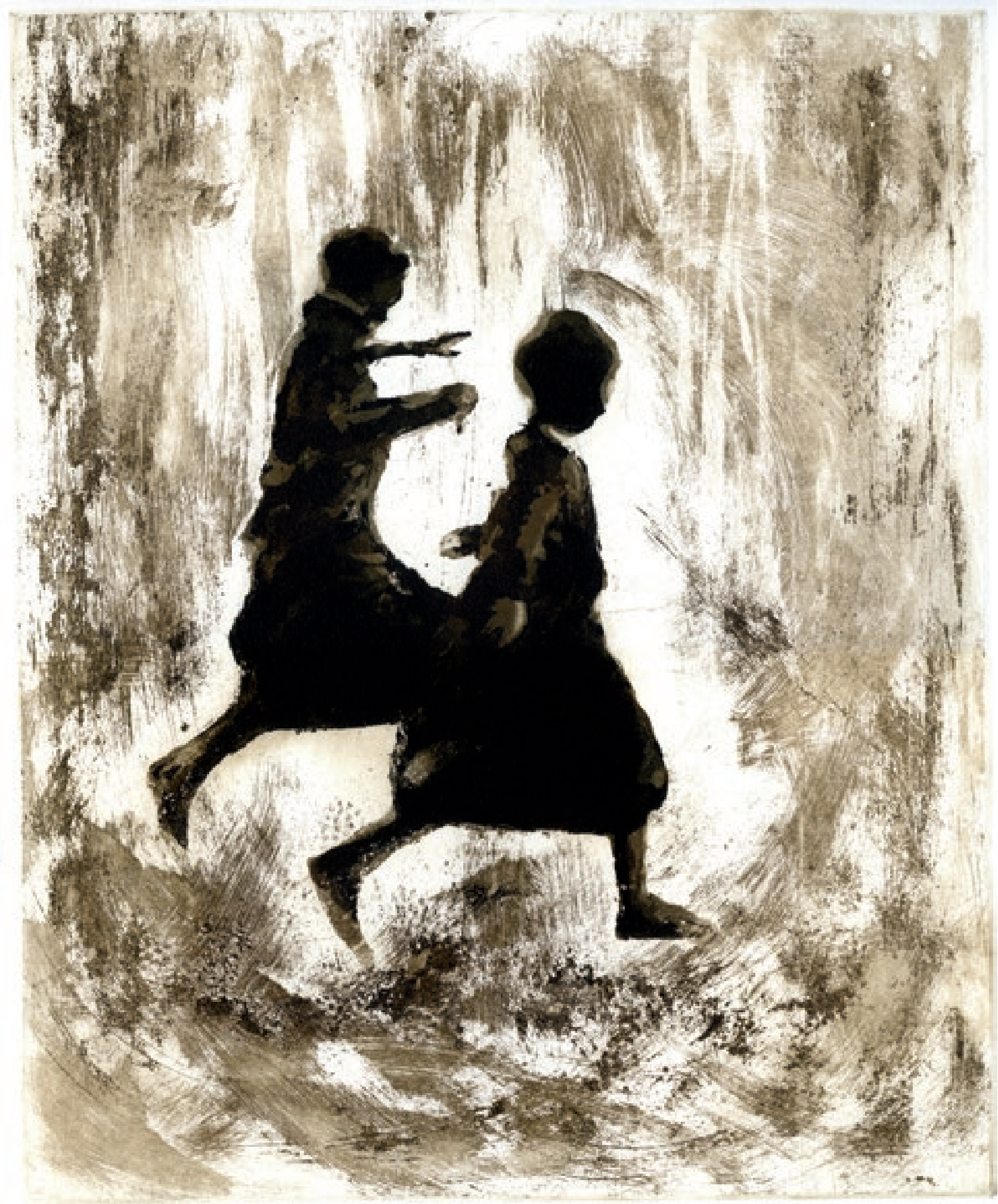




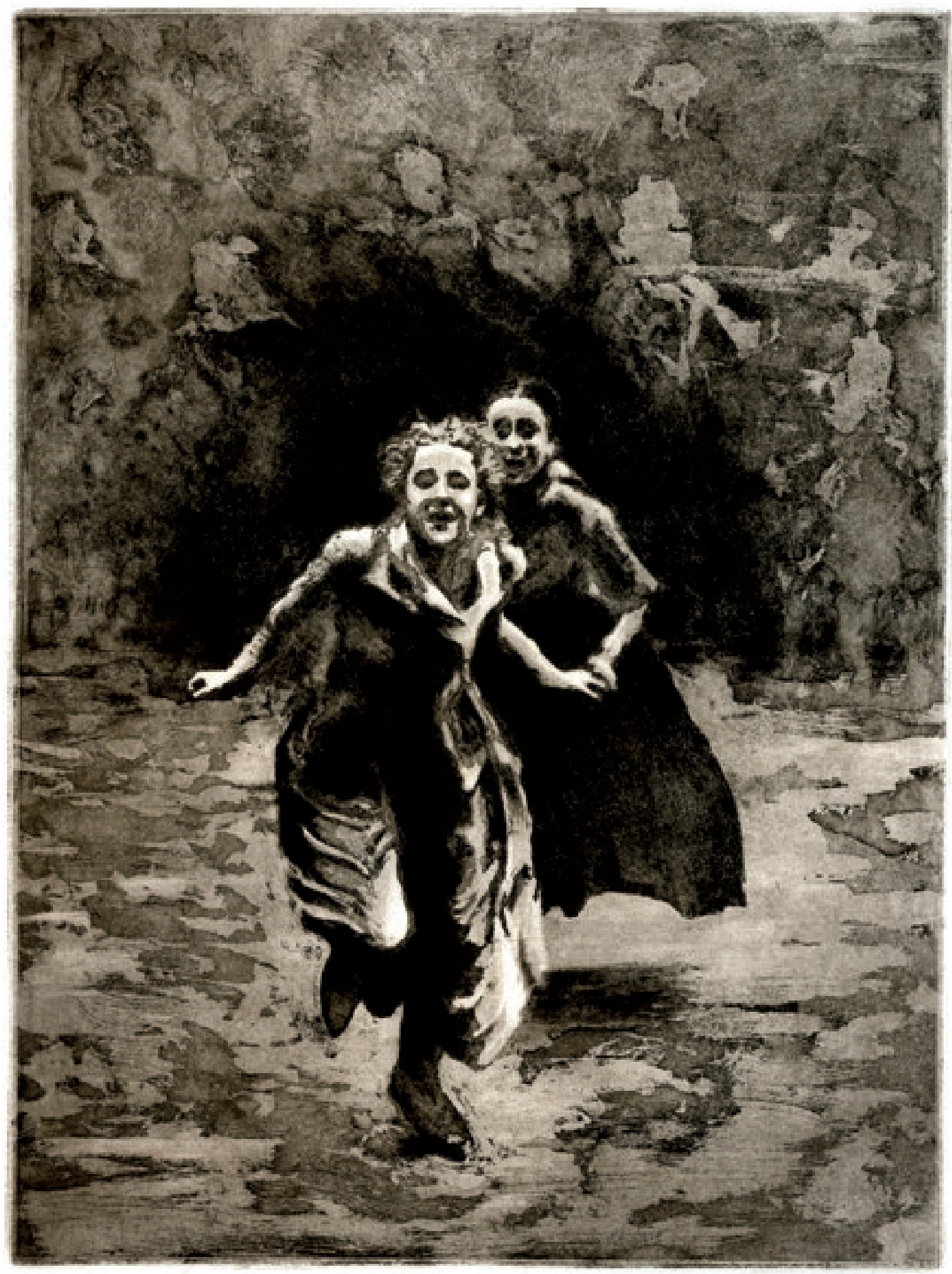




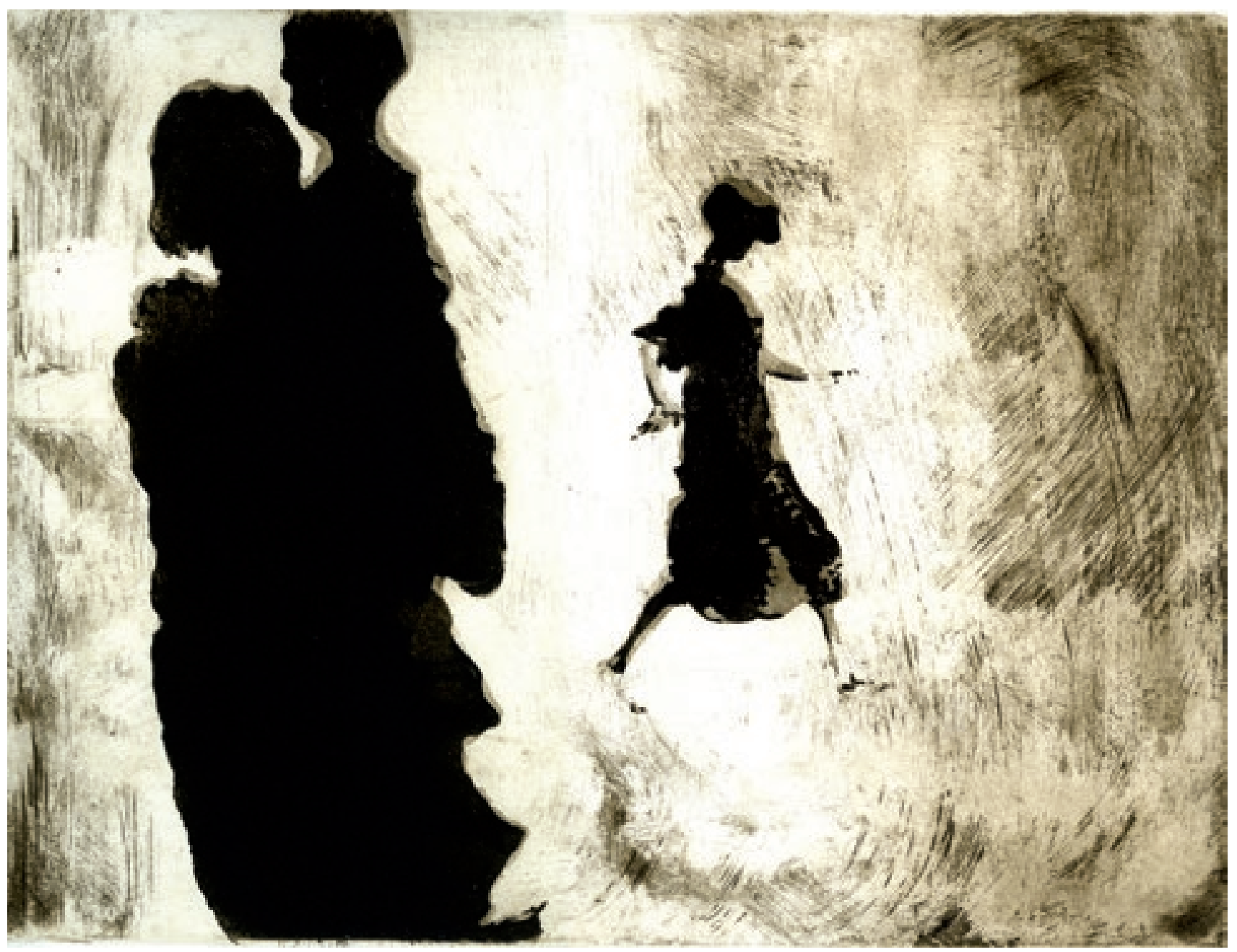

Metropolis 7 


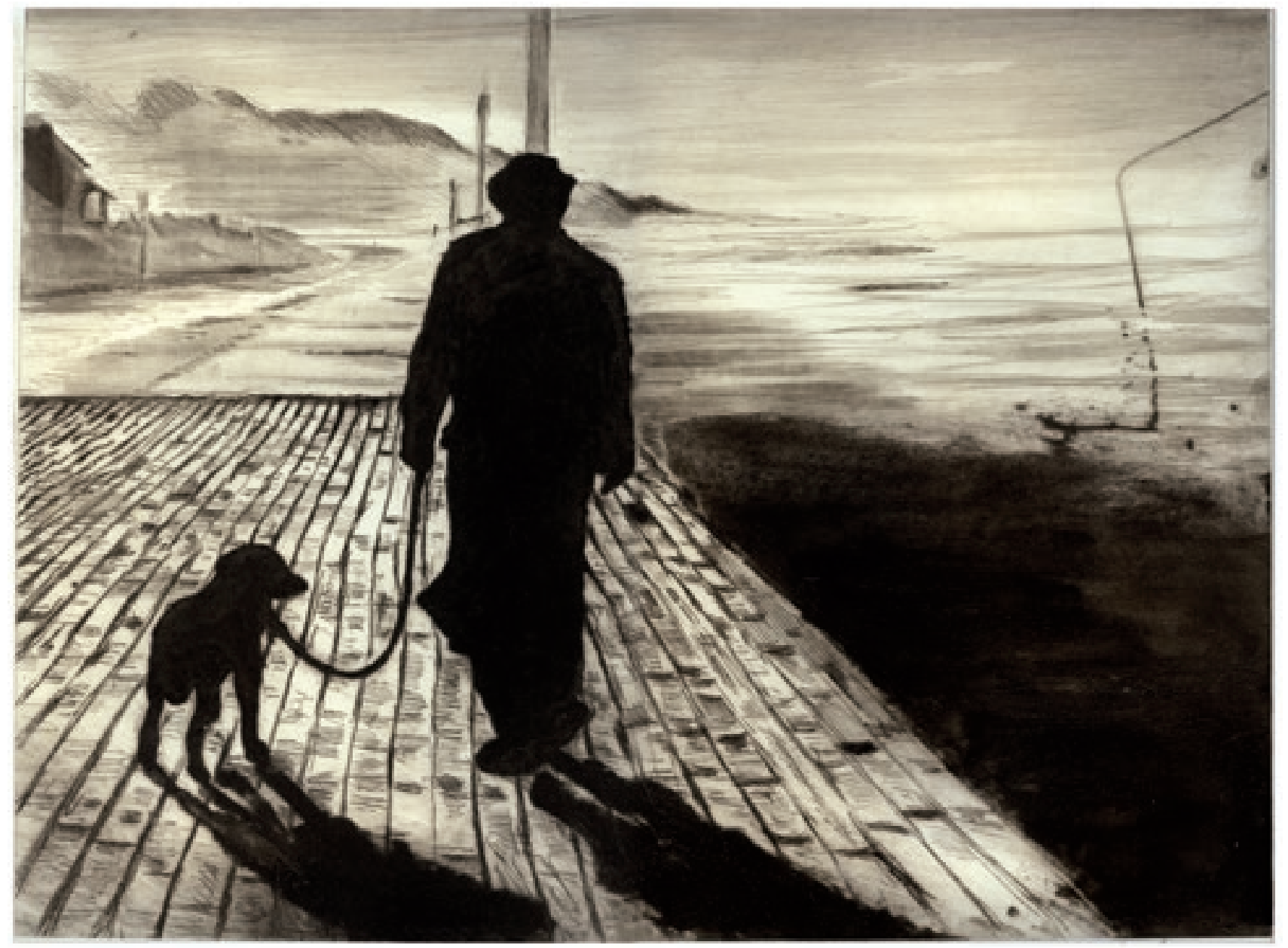

Un Homme et une femme (Claude Lelouch, 1966) 


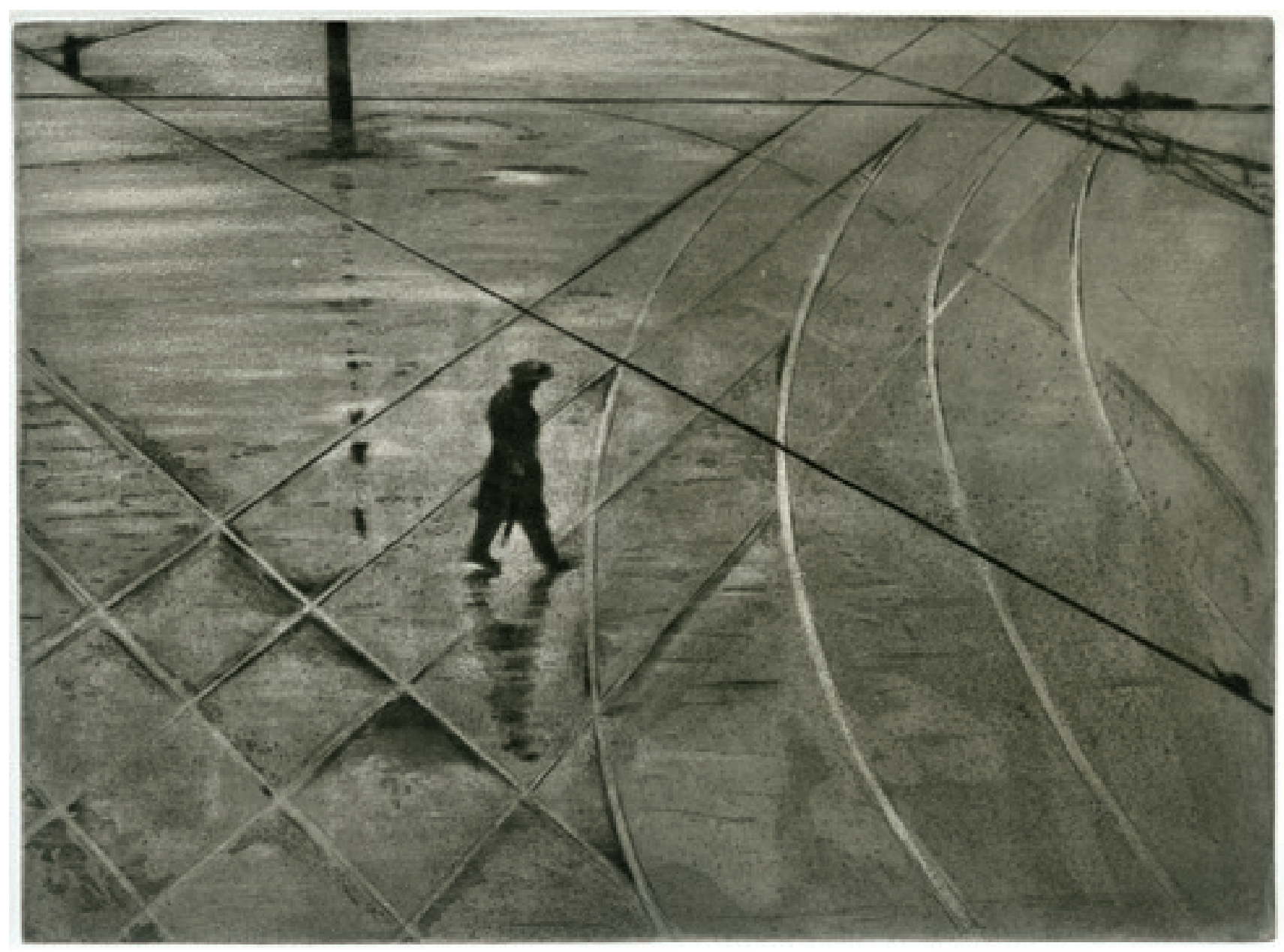

Le Nœud coulant (Wojciech Has, 1957) 